\title{
Polinizadores que visitam a espécie arbórea Myracrodrun urundeuva (Anacardiaceae) na borda oeste do pantanal, Assentamento Taquaral em Corumbá-MS
}

\section{Pollinators visiting a species of Myracrodrun urundeuva (Anacardiaceae) tree on the western edge of Pantanal, Taquaral Settlement in Corumbá-MS}

Valdinei da Conceição ${ }^{1}$ Aline Mackert dos Santos ${ }^{2}$

DOI Cristiano Almeida da Conceição ${ }^{3}$

10.30612/re-ufgd.v6i12.10782

\section{Recebido em 03/12/2019 - Aceito em 16/12/2019}

Resumo: A criação de abelhas no pantanal é uma atividade promissora, visto que neste ecossistema existe uma extensa pastagem apícola e quase absoluta ausência de uso de agrotóxicos. A apicultura e meliponicultura têm ambas potencial e espaço na cidade de Corumbá e região. No entanto, pouco se conhece sobre a pastagem apícola da região e sobre a fauna de abelhas. Este trabalho apresenta as ações de apicultores da Associação dos Apicultores Agricultura Familiar de Corumbá - AAAFC, e a observação de polinizadores que visitam a espécie arbórea Myracrodrun urundeuva (Anacardiaceae), conhecida popularmente como aroeira, por ser esta planta uma espécie protegida por lei e excelente fornecedora de recursos florais. As análises mostraram que cinco espécies de abelha sem ferrão utilizam os recursos florais da aroeira, sendo elas: Scaptotrigona depilis, Plebéia sp., Tetragonisca fiebrigi, Trigona chanchamayoensis e Oxytrigona tataíra.

Palavras chave: Apicultura; Meliponicultura; Trabalho coletivo; Educação Ambiental.

Abstract: Bee production in the Pantanal is a promising activity, since in this ecosystem there is extensive beekeeping pasture and almost absolute absence of pesticide use. Beekeeping and meliponiculture have both potential and space in the city of Corumbá and region. However, little is known about the region's beekeeping pasture and bee fauna. This paper presents the actions of beekeepers of the Associação dos Apicultores Agricultura Familiar de Corumbá - AAAFC, and the observation of pollinators visiting the tree species Myracrodrun urundeuva (Anacardiaceae), popularly known as aroeira, as this plant is a protected by law and excellent species supplier of floral resources. The analysis showed that five species of stingless bee use the floral resources of aroeira, namely: Scaptotrigona depilis, Plebéia sp., Tetragonisca fiebrigi, Trigona chanchamayoensis and Oxytrigona tataíra.

Keywords: Beekeeping; Meliponiculture; Collective work; Environmental education.

\section{Aspectos biológicos das abelhas}

As abelhas constituem o principal grupo de agentes polinizadores das plantas

\footnotetext{
1 Graduado em Ciências Biológicas pela Universidade Federal de Mato Grosso do Sul - Campus do Pantanal.

Email: Valdinei_taquaral@hotmail.com

2 Professora de graduação do curso de Ciências Biológicas da Universidade Federal de Mato Grosso do Sul Campus do Pantanal. Email: aline.m.santos@ufms.br

3 Doutorando em Geografia pela Universidade Federal da Grande Dourados. Email: cris87almeida@gmail.com
} 
floríferas por utilizarem uma dieta alimentar basicamente composta de produtos florais, néctar e pólen com algumas exceções, contribuindo para aumentar a produção de frutos e sementes. Tal fato confere a elas grande importância nas comunidades bióticas, a ponto de sua conservação ser considerada um fator essencial para a preservação das espécies vegetais. Além disso, sementes e frutos advindos da polinização são importantíssimos para a sobrevivência de uma série de aves e mamíferos nativos (AIDAR, 1996; KERR et al., 1996) e para o próprio ser humano.

Estão descritas, atualmente, cerca de 20 mil espécies de abelhas em todo o planeta, mas estima-se que existam de 25 a 30 mil. No Brasil, contabilizam-se 1576 nomes válidos, mas acredita-se que a fauna brasileira reúna pelo menos 3000 espécies (SILVEIRA et al., 2002).

Dentre as famílias de abelhas, Apidae é a que tem espécies com mais alto grau de desenvolvimento do comportamento social e compreende três subfamílias: Apinae, Nomadinae e Xylocopinae. Apinae por sua vez é dividida em 17 tribos, uma delas, Apini abriga quatro subtribos de abelhas corbiculadas, Apina (abelhas melíferas-africanizadas), Bombina (mamangavas de chão), Euglossina (abelhas das orquídeas) e Meliponina (as abelhas nativas sem ferrão) (SILVEIRA et al., 2002) que é representada por vários gêneros e centenas de espécies em todas as regiões tropicais do mundo, bem como nas regiões subtropicais do hemisfério sul.

As abelhas africanizadas apresentam característica polihíbrida resultante do cruzamento entre as raças africanas (Apis mellifera scutellata) com as subespécies europeias (A. m. mellifera; A. m. ligustica; A. m. carnicae e A. m. caucasica) existentes no continente americano antes da introdução das abelhas africanas no Brasil em 1956. As abelhas africanizadas atualmente encontram-se distribuídas desde o sul do Brasil até os Estados Unidos da América (EUA), apresenta características de melhor adaptação ao meio ambiente tropical em relação às subespécies europeias.

As abelhas da subtribo Meliponina (Hymenoptera, Apidae, Apini), também conhecidas como meliponíneos ou abelhas nativas sem ferrão não apresentam ferrão (ferrão atrofiado), entre elas podemos destacar as espécies conhecidas popularmente como: jataí, mandaçaia, Mandaguari, uruçu e arapuá.

Os meliponíneos estão restritos às regiões tropicais do mundo, e atualmente são identificadas mais de 400 espécies, distribuídas em quatro continentes (cerca de 300 espécies nas Américas, 60 no sudoeste da Ásia, 50 na África continental, quatro na Ilha de Madagascar e 10 na Austrália) (VELTHUIS, 1997). Mas uma estimativa precisa do número de espécies existentes ainda não é possível, devido à existência de espécies crípticas. Além disso, muitos gêneros e muitas áreas não foram adequadamente amostrados para o conhecimento de suas espécies (MICHENER, 2000). 
Todas as espécies de meliponíneos são forrageadoras generalistas e algumas espécies utilizam recursos de mais de 100 táxons de plantas ao longo das estações em um dado habitat (WILMS et al., 1996). A importância dessas abelhas para o ecossistema em geral pode ser avaliada tomando-se por base as informações de KERR et al. (1999), que dizem ser os meliponíneos responsáveis por até $90 \%$ da polinização das plantas fanerógamas em alguns ambientes.

\section{Aspectos econômicos}

A criação de abelhas com ferrão ou apicultura (criação de abelhas da espécie Apis mellifera) utilizando métodos e equipamentos sem sistema de confinamento, alojando em colmeias artificiais, sob controle do homem, visa cultivar e melhorar a produtividade em busca de explorar a capacidade natural dos insetos (REIS et al., 2003).

A apicultura é uma atividade que não necessita de grandes áreas para o seu desenvolvimento, podendo ser desenvolvida por agricultores de médio e grande porte, sendo capaz de causar impacto positivo no orçamento familiar, pela produção de mel, geleia real, pólen, própolis e cera. Esta atividade consorciada com agricultura aumenta a qualidade dos frutos. Sem contar que o açúcar produzido pelas flores, que seria desperdiçado, será coletado, pelas abelhas e transformado em mel.

Segundo dados do SEBRAE (2009) a quantidade de mel produzida no Brasil aumentou nos últimos cinco anos, tendo um aumento significativo de mais de $50 \%$, estima-se que a produção esteja em torno de 40 a 45 mil toneladas por ano. No ano de 2001 o Brasil iniciou as exportações de mel para a Europa e Estados Unidos, sendo que esta produção anteriormente era consumida no mercado interno brasileiro.

Com início das vendas para o mercado internacional algumas mudanças foram geradas, o que provocou novas adequações na cadeia produtiva da apicultura, e também houve a necessidade de estabelecer normas de qualidade do produto, que este mercado exige, havendo a necessidade de criar espaços de diálogos como fóruns internacionais visando garantir a qualidade e a comercialização dos produtos apícolas.

Embora produzam mel em menor quantidade, os meliponíneos fornecem um produto diferenciado do mel de Apis mellifera, pela doçura e aroma inigualáveis, possuindo consumidores distintos, dispostos a pagar altos preços pelo produto no mercado (CARVALHO et al., 2005). Devido à escassez de informações sobre a prática da meliponicultura, e da composição do mel produzido pelas abelhas sem ferrão e das fontes de recursos alimentares utilizados pelas mesmas, 
pesquisas se fazem necessárias para possibilitar estratégias futuras de utilização racional da flora e destes insetos.

A retirada do mel de abelhas nativas sem ferrão é feita de forma rústica, e em geral sua utilização também. Este mel é utilizado como remédio, na fabricação de xaropes para gripe. A própolis junto com pólen e a cera colocada no álcool ou na pinga e usado no tratamento de dor de garganta. O mel também pode ser utilizado para limpar os olhos.

Pela sua natureza, a apicultura é uma atividade conservadora das espécies, sendo das poucas atividades agropecuárias que preenchem todos os requisitos do tripé da autosustentabilidade: o econômico, porque gera renda para o agricultor; o social, porque ocupa mão-deobra familiar no campo; e o ecológico, porque não se desmata para criar abelhas (ALCOFORADOFILHO, 1998), da mesma forma a meliponicultura pode ser considerada autossustentável. Atividades autossustentáveis propõem a obtenção de produtos que possam ser repostos pelo próprio ecossistema, num ciclo definido, possibilitando renda aos proprietários da terra, e ao mesmo tempo mantendo o equilíbrio desejado dos ecossistemas.

\section{Aroeira e suas utilidades}

A "Aroeira", espécie arbórea Myracrodruon urundeuva, pertencente à família Anacardiaceae, sendo esta espécie de ocorrência tropical, secundária distribuída do norte ao sul do Brasil. Esta planta é frequente em matas de cerrado de solos calcários, argilosos ou arenosos, não inundável e também encontrada na Argentina e no Paraguai. Esta espécie quando amadurecida pode chegar até 20 metros de altura, a sua casca escura e áspera, as folhas cheiram à manga é e palatável comestível pelos bovinos e demais animais.

A casca curtida em água é bastante utilizada na medicina caseira para tratamento de diarreia, ferida em animais de pequeno, grande porte e humanos. Além disso, a casca pode ser fervida até formar uma pasta escura para ser usada no tratamento de quebradura. A casca curtida também é utilizada com tintura para curtir couro para fabricação de artesanatos e tralha de areio. A madeira produzida por esta espécie arbórea é bastante pesada e requisitada para construção de móveis, dormente de trilho de linha de ferro, cerca, moirão de curral, e moenda de engenho devido à durabilidade do seu tanino.

Esta espécie possui um grande potencial apícola, sendo o seu período de floração localmente entre os meses de julho a agosto, é utilizada na produção de mel pelas Apis mellifera, o mel elaborado por esta espécie de abelha possui uma coloração âmbar diferenciando de outras 
floradas (Figura 1). E na região de Corumbá esta espécie arbórea é uma das poucas que floresce neste período do ano que coincide com o período de seca.

Figura 1 - Comparação da coloração do mel produzido em floradas normais, mais claro (A) e o mel produzido na florada da aroeira, coloração âmbar (B).

\section{A}

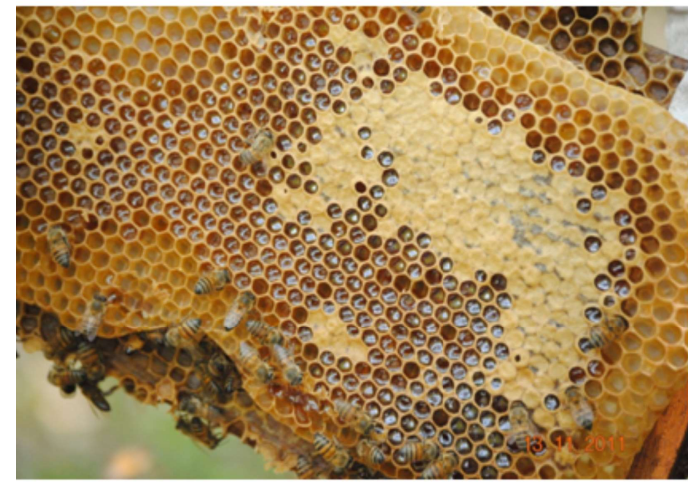

B

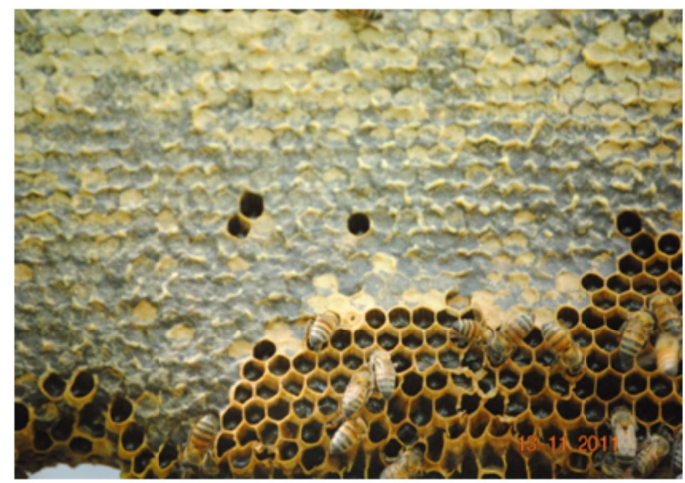

Fonte: CONCEIÇÃO, 2013

\section{Panorama do mel no Assentamento Taquaral}

A apicultura no município de Corumbá ainda não está totalmente consolidada, não sendo uma fonte significativa geradora de renda nesta região. No Assentamento Taquaral esta atividade começou a ser desenvolvida no ano de 1997 apoiados pela Comissão Pastoral da Terra (CPT). No mesmo ano os produtores financiaram pelo Banco Brasil a compra de equipamentos para o início desta nova atividade. Neste período os produtores trabalharam de forma informal produzindo o mel e comercializando no mercado local, e com o aumento da produção e com exigências das normas sanitárias para comercialização do mel no mercado e venda para compra direta do governo federal novas oportunidades de negócios surgiram.

Com isto, no ano de 2011 foi criada a Associação dos Apicultores da Agricultura Familiar de Corumbá (AAAFC), com intuito de difundir cada vez mais esta atividade no meio rural. A associação conta com 20 associados trabalhando em sistema coletivo.

Em 2011, a associação foi contemplada através de edital da comunidade participativa com recursos de 20 mil reais para aquisição de colmeias e equipamentos de proteção individual. Neste período foi formado três grupos de apicultores para trabalharem de forma coletiva com a atividade e cada grupo recebeu 15 colmeias, e 5 colmeias foram destinadas para a Escola Municipal Rural Polo Monte Azul para serem utilizadas na educação ambiental dos alunos. A AAAFC juntamente com a equipe pedagógica da escola instalou um apiário nas imediações da escola para servir de laboratório nas aulas de ciência e toda a produção de mel destas 5 colmeias eram 
revertidas na merenda da escola. É importante ressaltar que a AAAFC realizava palestra de educação ambiental para todos os alunos da escola e a $9^{\circ}$ serie era responsável de acompanhar o manejo guiado pelos associados da AAAFC. O projeto de apicultura na escola durou até o ano de 2014, e seu encerramento foi pela falta de professor em continuar o projeto na escola.

No ano de 2014 a AAAFC conseguiu apoio para a construção da "Casa do Mel". Este apoio para a construção da "Casa do Mel" veio através de dois alunos que ao final do curso de Pós-graduação lato sensu Residência Agrária da Universidade Federal da Grande Dourados (UFGD), viabilizaram recursos financeiros no valor de oito mil reais. Com o valor repassado a associação adquiriu os materiais de construção como: tijolos, cimento, telhas, portas, foro, janelas e parte do piso. Ao mesmo tempo, a associação também recebeu do governo estadual equipamentos apícolas para ajudar no beneficiamento e na agregação de valor.

Em setembro de 2015 foi realizada a $1^{\circ}$ Festa do $\mathrm{Mel}$, evento que obteve destaque local e regional a partir da divulgação na mídia pela afiliada da Rede Globo a TV Morena. A festa foi organizada pela Associação dos Apicultores da Agricultura Familiar de Corumbá - AAAFC, em parceria com a comunidade católica de Santo Antonio e contou com apoio de diversas instituições públicas e empresas privadas de Corumbá. O objetivo da festa era divulgar o trabalho da associação e popularizar o consumo do mel e desmitificar que o mel não é remédio e sim alimento.

Portanto, a realização da festa ampliou a divulgação do trabalho da associação e a partir disso a entidade foi convidada a participar do programa Agroindústria Familiar. Com a participação da associação no programa Agroindústria Familiar houve a possibilidade de criação da logomarca do mel, além da construção do manual de manipulação e boas práticas, elemento fundamental para solicitação do Serviço de Inspeção Sanitária (SIM). Atualmente a AAAFC é certificada com o SIM para envasar o mel e comercializar no mercado municipal. A Figura 2 apresenta logomarca utilizada para a comercialização do mel. O mel da AAAFC pode ser encontrado em mercados, mercearias, farmácias, casa de embalagens e cantinas escolares. Outro importante mercado acessado recentemente é a entrega de mel no Programa de Aquisição de Alimentos - PAA (Institucional) no Centro de Intendência da Marinha em Ladário.

Figura 2. Rotulo utilizado no mel comercializado no mercado varejo da cidade de Corumbá. 


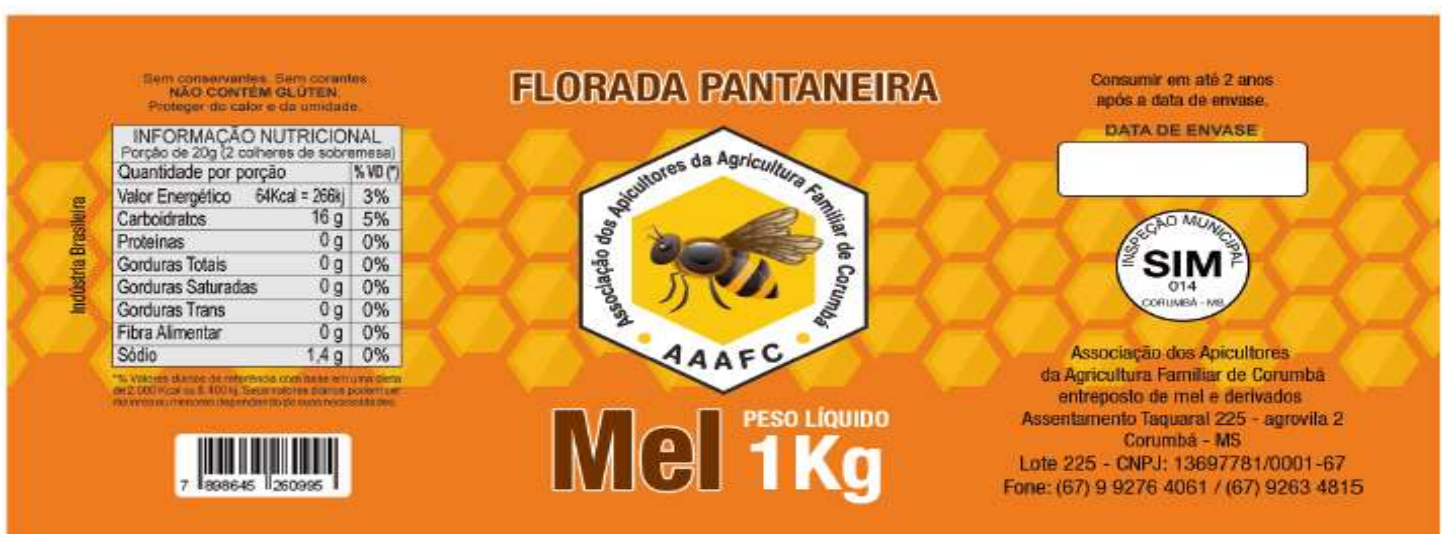

Fonte: CONCEIÇÃO, C.A. (2018).

No início do ano de 2018 a AAAFC se cadastrou no programa PROVE Pantanal ${ }^{1}$ para receber os benefícios que a lei oferece na isenção de impostos para a pequena agroindústria no momento de efetuar a venda ao comercio.

\section{Materiais e Métodos}

O estudo foi realizado no assentamento Taquaral pertencente ao município de Corumbá. O assentamento está localizado nas coordenadas $19^{\circ} 02^{\prime}$ a $19^{\circ} 10^{\prime}$ de latitude Sul e $57^{\circ}$ $37^{\prime}$ a $57^{\circ} 44^{\prime}$ de longitude Oeste de Greenwich.

O assentamento Taquaral dispõe de uma área total de 10. 013,24 ha. Desta área total apenas seis mil hectares foram destinados para reforma agrária, dividido em 394 lotes tendo em média 12 a 20 ha cada. O restante da área corresponde a aproximadamente 3.434,387 que foi destinado para constituição da reserva coletiva. Três lotes do assentamento foram utilizados para este estudo: área 1 localizada no lote 262 (coordenadas $19^{\circ} 06^{\prime} 50.2^{\prime}$ Sul e $05^{\circ} 43^{\prime} 35.6^{\prime}$ de longitude Oeste de Greenwich); área 2 localizada no lote 276 (coordenadas $19^{\circ} 09^{\prime}$ 03.5' Sul e $057^{\circ} 44^{\prime}$ '12.6' Oeste de Greenwich) e área 3 localizada no lote 225 (coordenadas $19^{\circ} 06^{\prime}$ 05.2' Sul e $057^{\circ} 41^{\prime} 45.5^{\prime}$ Oeste de Greenwich) (Figura 3).

A escolha dos pontos ocorreu mediante análise antecipada do local visitado um mês antes do início das coletas. O parâmetro de seleção dos pontos incluiu a altura das árvores, que deveria ser de 3 a 5 metros, estes cuidados foram tomados para não dificultar as atividades e o acesso. Esta visita teve como objetivo de homogeneizar as áreas de estudos.

Para o desenvolvimento do ensaio foram delimitadas três áreas de captura, com a

1Decreto $\mathrm{n}^{\circ} 9.983$ de 17/07/2000 que estabelece normas especiais de tratamento simplificado e diferenciado e dispõe sobre o tratamento tributário dispensado à Unidade Familiar de Processamento Agroindustrial - UFPA. 


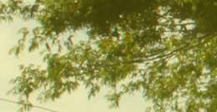

área de coleta na dimensão de 0,5 hectares cada. Estas áreas têm em média trinta exemplares de aroeira. $\mathrm{Na}$ área de captura foram demarcados quais arvores seriam pontos de coleta.

Figura 3 - Região do Assentamento Taquaral evidenciando os pontos de coleta.

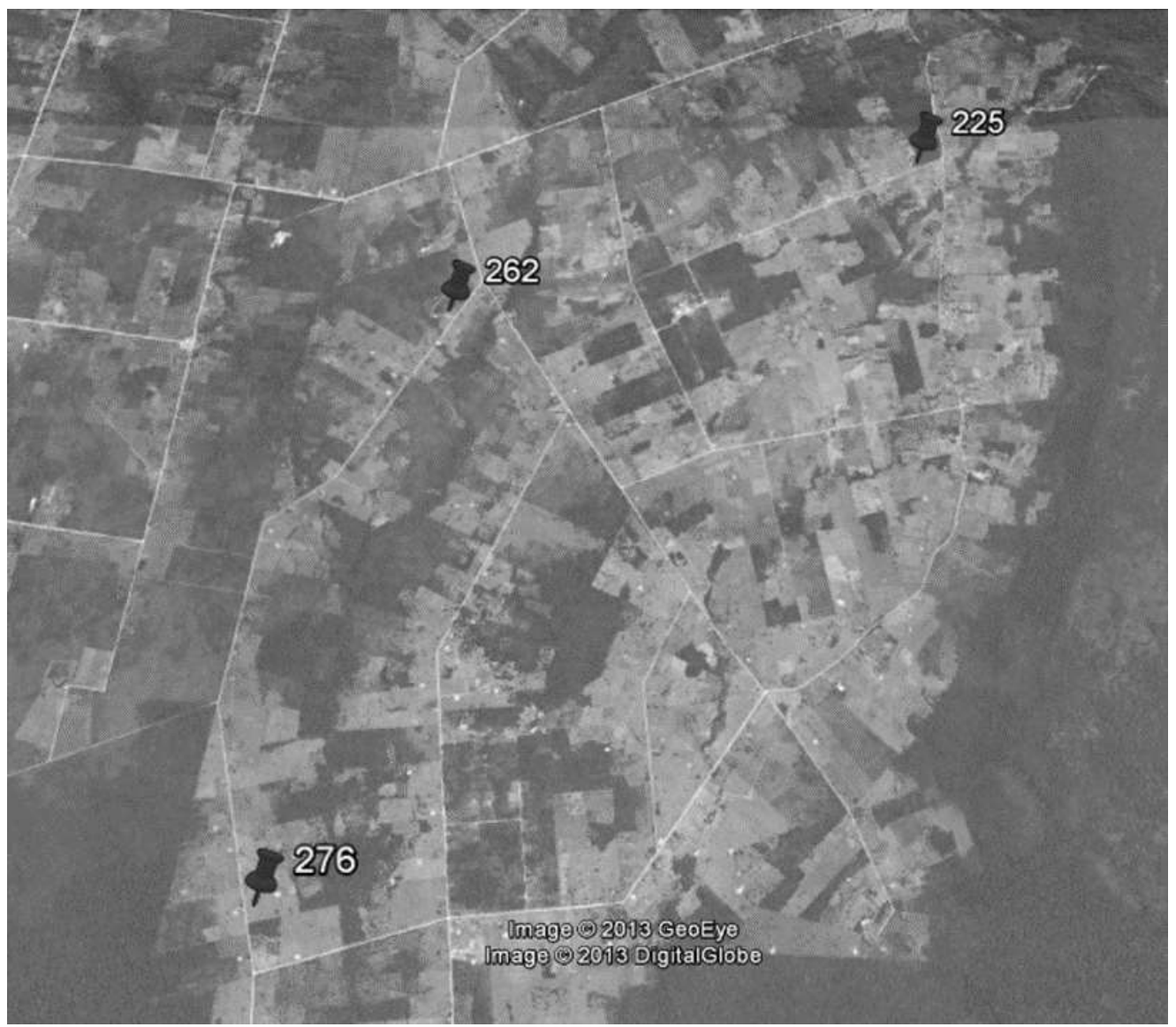

Fonte: Google Earth.

\section{Identificação de polinizadores de Aroeira}

Para a coleta de abelhas visitantes da espécie arbórea aroeira (Myracrodrun urundeuva) a campo, utilizou-se os seguintes materiais: rede entomológica; frasco de vidro contendo éter embebido em algodão; frascos médios de plástico para armazenar os exemplares; fita adesiva; agenda; caneta; máquina fotográfica; GPS para demarcar as áreas, bolsa para transporte das amostras.

A captura das abelhas foi realizada entre os meses de julho a agosto do ano de 2012, período em que a aroeira perde as folhas e florescem. Estabeleceu-se seis horas diárias de coleta, sendo três horas no período matutino (8:00 as 11:00) e três horas no período vespertino (14:00 as 17:00), e ocorrendo três vezes semanalmente, um dia em cada ponto mantendo-se 15 minutos em 
cada árvore. As abelhas africanizadas (Apis mellifera) visitantes florais não foram amostradas neste estudo.

Os insetos capturados foram montados em alfinete entomológico, etiquetados e secos em estufa por 24 horas. Os insetos foram agrupados conforme sua morfologia, e separados em ordem. As abelhas foram identificadas em menor nível taxonômico possível utilizando chaves de identificação publicadas em Silveira et al. (2002). Os meliponíneos foram identificados até o nível de gênero. Ao término deste procedimento o material foi mantido em coleção entomológica no Laboratório de Zoologia do Campus do Pantanal.

No item seguinte serão apresentados os insetos e a frequência de ocorrência a partir dos pontos de coletas.

\section{Resultados e Discussão - Polinizadores da "aroeira" Myracrondun urundeuva}

As áreas utilizadas para coletas de espécies de insetos visitantes de "aroeira" apresentaram vegetação em diferentes estágios de conservação. A estatura média das árvores de aroeira foi de cinco metros de altura, sendo que a escolha do porte das árvores teve o intuito de favorecer a observação e captura das abelhas visitantes com a rede entomológica.

Nas áreas 1 e 2 a vegetação foi parcialmente desmatada para o cultivo de lavoura. Hoje a área 1 está sendo utilizada para criação de gado de modo rudimentar. A área 2 está sendo utilizada para criação pecuária leiteira. Esta área localiza-se próxima a uma das reservas coletivas do assentamento. A área 3 possui 1 hectare de sua área preservada para a execução de atividades apícolas, mas a maior parte foi desmatada inicialmente para o cultivo de lavoura (milho, arroz, feijão, mandioca e algodão) e hoje está área está voltada para o desenvolvimento da pecuária leiteira. Praticamente todo o tipo de vegetação nestes ambientes foi dizimado, bem como os insetos sociais (abelhas) que se encontravam alojados em troncos de árvores.

Durante o período de amostragem nas áreas foram coletados 136 exemplares de insetos coletores de néctar e/ou pólen. De acordo com a identificação dos insetos dentre os 136 exemplares observou-se a maior incidência da ordem Hymenoptera (83\% das visitas), seguido de Díptera com 14\% e 3\% de Lepidoptera (Gráfico 1). 
Gráfico 1 - Gráfico mostrando a freqüência de insetos coletados na "aroeira” Miracrondum urundeuva nas três áreas de coletas pertencentes às ordens: Himenóptera, Díptera e Lepidóptera

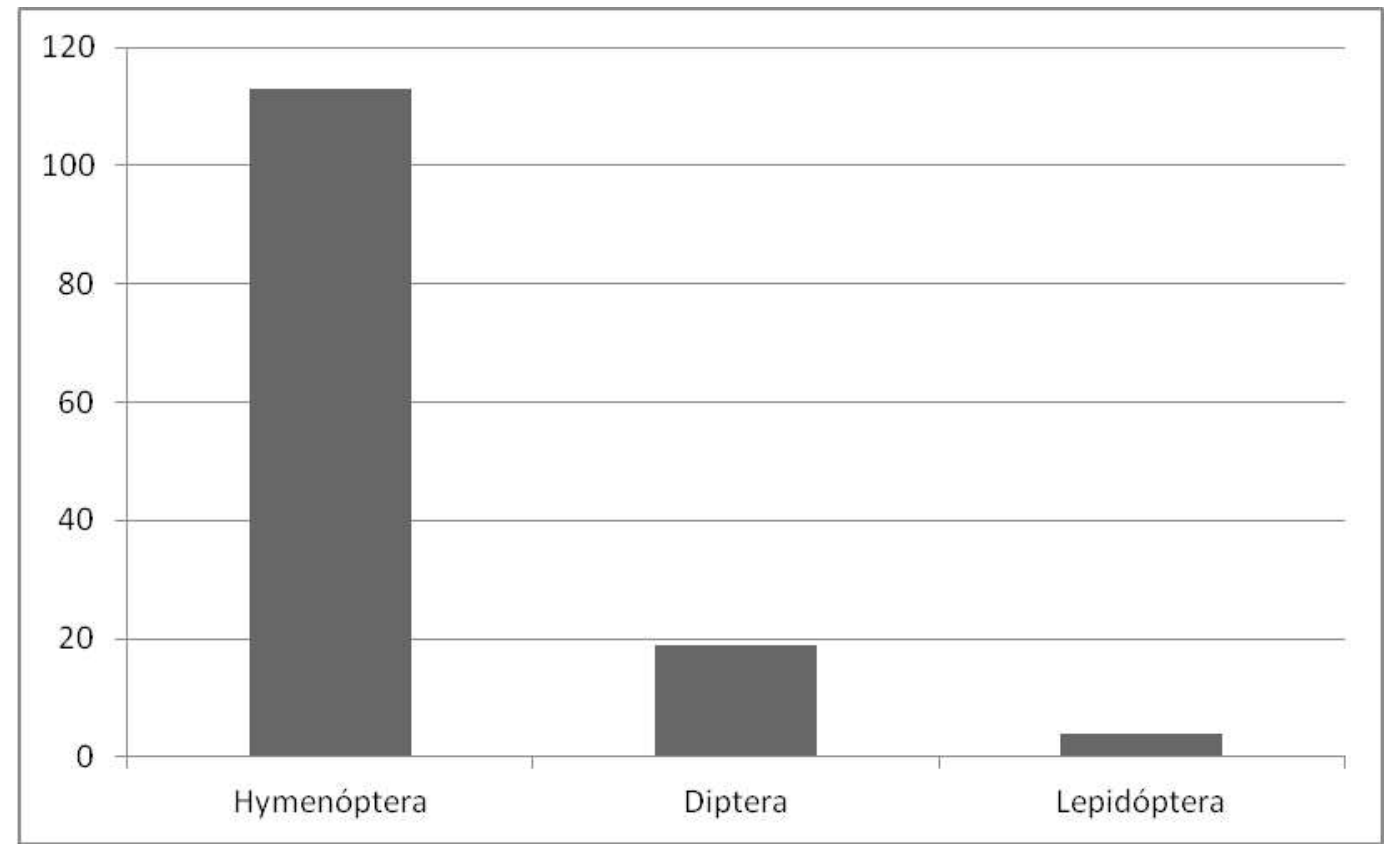

Fonte: Trabalho de campo.

Em relação às abelhas foram amostradas nas áreas de coleta abelhas da família Apidae (82\%) e Halictidae (18\%). A família Halictidade, conhecida popularmente como abelhas do suor, constitui-se de abelhas pequenas com coloração metálica e que não são produtoras de mel. Em relação à família Apidae foram identificadas apenas abelhas pertencentes à subtribo Meliponina (abelhas nativas sem ferrão). Os Meliponina foram identificadas em gênero, sendo que Scaptotrigona (S. depilis) correspondeu a $49 \%$ do total de abelhas coletadas, Tetragonisca ( $T$. fiebrigi) correspondeu a $12 \%$, o gênero Oxytrygona (O. tataira tataira) correspondeu a $5 \%$ e os gêneros mais raros foram Plebéia (espécie não identificada), correspondendo a apenas $2 \%$ do total de abelhas coletadas, e Trigona (T. chanchamayoensis) correspondendo a 1\% (Gráfico 2). 
Gráfico 2 - Frequência de visitas de abelhas nas flores de "aroeira" Miracrondum urundeuva

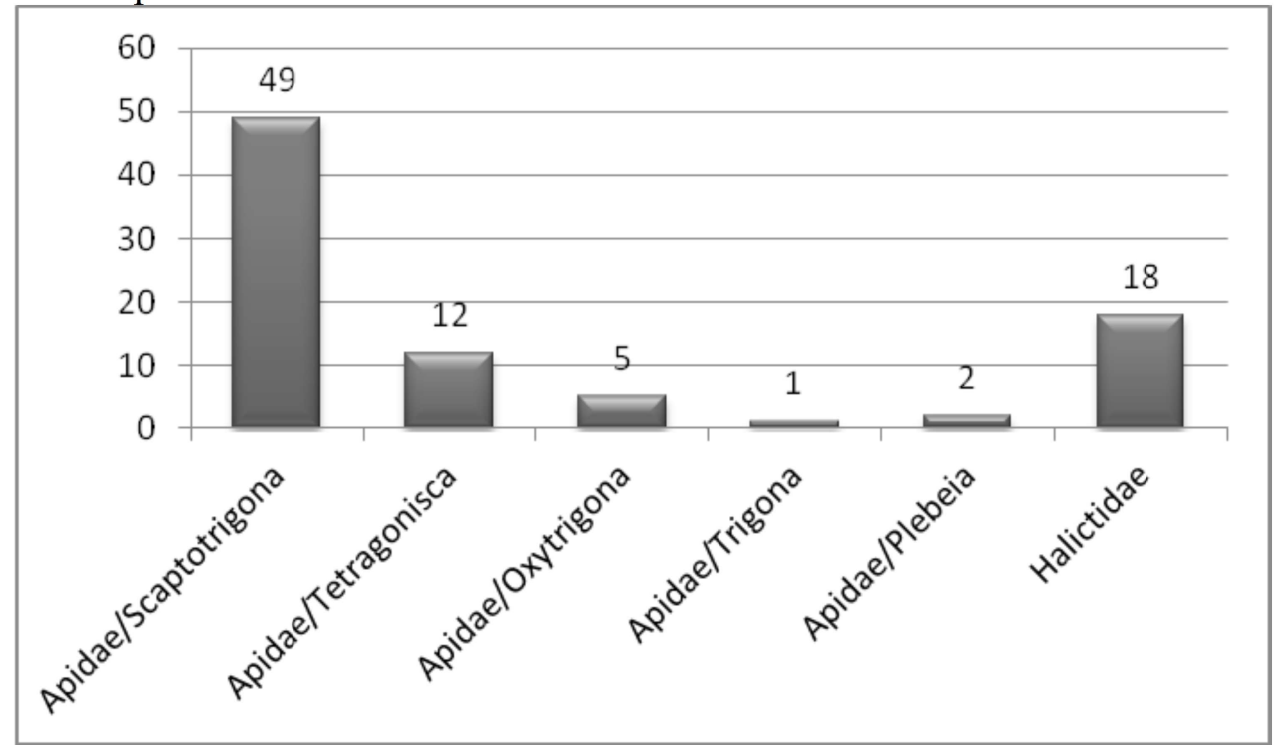

Fonte: Trabalho de campo.

Entre os Meliponina, os gêneros Scaptrigona e Tetragonisca, conhecidas popularmente como Mandaguari e jati (ou jataí), respectivamente, apresentam potencial para atividade de criação de abelhas, seja para produção de mel ou própolis. O mel de jati é muito apreciado, tem valor agregado maior que o mel de abelhas africanizadas, é boa produtora de mel, e seu mel é muito higiênico. A Mandaguari possui colônias grandes, produzem grandes quantidades de mel. Uma informação adicional importante é que estas abelhas são abundantes tanto nas flores de aroeira quanto nas demais florais, sendo que seus ninhos são de fácil acesso e retirada.

As abelhas do gênero Trigonae Oxytrigona não são recomendadas para atividade de criação de abelhas. O gênero Trigona, conhecido popularmente como arapuá possui hábitos não higiênicos, coletando fezes para construção de seus ninhos, o que pode causar contaminação no mel. Já o gênero Oxytrigona,conhecido popularmente pelo nome "caga-fogo" ou tataíra, produzem mel de pouca qualidade e são muito agressivas, liberando um liquido caustico sobre a pele de seus inimigos, o que faz com que os meliponicultores não gostem de sua presença próximo a suas propriedades. O gênero Plebeia conhecida popularmente como Mirim-guaçú, foi pouco amostrada, porém seu mel é muito apreciado e tem preço alto no mercado, principalmente devido ao fato da quantidade de mel produzida por esta abelha ser muito pequena.

\section{Conclusões}

Cinco gêneros de abelhas sem ferrão visitaram as flores de aroeira. As observações em campo mostraram que a aroeira pode ser utilizada como recurso floral para os meliponíneos. Dentre os meliponíneos a Mandaguari (Scaptotrigona depilis) e a Jatí (Tetragonisca fiebrigi) 
utilizam com maior frequência os recursos florais produzidos pela aroeira, com potencial para produção de mel e própolis. E o gênero Plebeia apresentou menor viabilidade para produção de mel através da florada da aroeira por ter visitas raras a esta espécie e por produzir pouco mel.

A aroeira além de ser uma espécie protegida por lei encontrada nos lotes, como fonte de manutenção, ou sombra para o gado pode ser mais uma fonte de renda agregando valor ao orçamento familiar produzindo um mel diferenciado. $\mathrm{O}$ assentamento Taquaral tem um grande potencial para o desenvolvimento da atividade apícola por apresentar uma vasta pastagem apícola isenta de agrotóxico.

Com estas características o mel produzido a partir da florada da aroeira futuramente pode ser reconhecido com um mel típico da Borda Oeste do Pantanal. A instalação do apiário na Escola Monte Azul foi de grande importância para difundir as técnicas de manejo e incentivar novos adeptos a entrar nesta atividade, que é promissora e tende a se expandir cada vez mais no pantanal, devido ao fato deste local apresentar todas as características ideais para o desenvolvimento de atividades de criação de abelhas, por ser uma vasta pastagem apícola isenta de agrotóxico.

Após a realização da festa do mel em 2015, a AAAFC passou a ser convidada a ministrar palestras de educação ambiental e geração de rendas em escolas nos municípios de Corumbá e Ladário e outra importante forma de ampliar os benefícios da apicultura ocorre com as visitas de alunos da rede pública particular no apiário e na casa do mel. Além disso, é constante a procura de novos interessados que estão com objetivo de desenvolver atividade em sua propriedade.

\section{Referencial bibliográfico}

AIDAR, D.S. A mandaçaia: Biologia de abelhas, manejo e multiplicação artificial de colônias de Melipona quadrifasciata Lep. (Hymenoptera, Apidae, Meliponi-nae). Série Monografias 4, Braz, Journ. Genetics, 1996,104p.

ALCOFORADO-FILHO, F.G. Caatinga: florística, manejo e sustentabilidade. In: CONGRESSO NACIONAL DE BOTÂNICA,49, Salvador. Resumos, Salvador: UFBA.SBB. 1998, p 437438.R1030.

CARVALHO, C. A. L. et al. Mel de abelha sem ferrão: contribuição para a caracterização físicoquímica. Cruz das Almas: Universidade Federal da Bahia/SEAGRI-BA. 2005.

KERR, W. E. ; CARVALHO, G.A. \& NASCIMENTO, V.A. Abelha Urucu: Biologia, Manejo e Conservação. Ed: Acangaú, Belo Horizonte MG.1996. 
